\title{
LOS OFICIALES DE LA MAR ANDALUCES DE LA PRIMERA MITAD DEL SIGLO XVIII.
}

\author{
$\mathbf{M}^{a}$ Del Mar Barrientos Márquez. \\ Universidad de Cádiz
}

\section{RESUMEN}

El trabajo que aquí se presenta se circunscribe a la Carrera de Indias, se apunta hacia el estudio del elemento humano de la Carrera, exactamente a un sector, como era el de los oficiales. El objetivo es analizar una parte de la historia de estos hombres que a menudo se ha pasado por alto, como es la historia de sus vida: familias, hijos, objetivos, aspiraciones, muerte, etc., etc., queremos ofrecer una perspectiva desde la vida cotidiana de hombres que formaban parte de una familia, que viven, arriesgan y mueren, la mayoría, sin ver cumplidas sus perspectivas de futuro. Un punto de vista más humano o más cercano a sus vidas.

\section{ABSTRACT}

The present study focuses on the Carrera de Indias (Colonial Convoy System) and points towards the analysis of the human elements of the Carrera, more specifically, the officers group. The main aim is to investigate one aspect of the history of these men that very often has been overlooked, that is, their personal life: family, children, objectives, aspirations, death, etc... We intend to offer a new perspective from the point of view of the daily life of these men as part of a family, men who, in most cases, live, risk and die without achieving their expectations.

La Carrera de Indias: sus barcos, travesías, negocios, etc., etc. ha sido tratada con profundidad por los historiadores en numerosas ocasiones. El trabajo que aquí presentamos, aunque circunscrito en dicho marco, apunta hacia el estudio del elemento humano de la Carrera, exactamente a un sector, como era el de los oficiales. Nuestro 
objetivo fue analizar una parte de la historia de estos hombres que a menudo la hemos pasado por alto, como es la historia de sus vida: familias, hijos, objetivos, aspiraciones, muerte, etc., etc., pues debajo del escenario de la Carrera de Indias late la pequeña historia intima de familias, que como un medio de vida hicieron uso de ella. Queremos ofrecer una perspectiva desde la vida cotidiana de hombres que formaban parte de una familia, que viven, arriesgan y mueren, la mayoría, sin ver cumplidas sus perspectivas de futuro. Quizás, y porqué no, un punto de vista más humano o más cercano a sus vidas.

El estudio lo delimitamos geográfica y cronológicamente a la Andalucía marinera de la primera mitad del siglo XVIII. Hay que tener presente que desde la antigüedad, toda la costa de la región estuvo abocada a la mar, pero sobre todo será la zona de la bahía gaditana la que posteriormente tras el descubrimiento ha mantenido un vínculo más fuerte con Indias, acrecentando el espíritu marinero y comercial de sus gentes, y ejerciendo atracción sobre los vecinos de otros centros urbanos que irán llegando a la capital gaditana, lugar de partida de la flota.

El siglo XVIII, si no cambió en lo sustancial la situación de atraso general de la marina, si introdujo ciertas modificaciones que dieron lugar al renacimiento del poder naval y militar español, imprescindible para mantener el dominio de los mares y salvaguardar la integridad del imperio a ambas orillas del Atlántico; dentro de esta línea fue objetivo prioritario de la Corona reorganizar la Carrera de Indias. De ahí, las innumerable reformas y leyes dictadas durante toda la centuria, y que verán su fruto en el último tercio del siglo XVIII.

La documentación empleada para nuestro trabajo ha sido principalmente los autos de Bienes de Difuntos que se localizan en la sección de Contratación del Archivo General de Indias. Estos fondos son excepcionales por la información que nos ofrece acerca de la mentalidad, sentimientos, formas de vida, etc. La Casa de la Contratación, primera institución creada en la Península para la administración del Nuevo Mundo, tuvo entre sus muchas atribuciones, la de hacer llegar los bienes de los fallecidos en América sin herederos a sus legítimos sucesores en la Península. En el complicado sistema político-administrativo indiano, se crearon a mediados del siglo XVI los llamados Juzgados de Bienes de Difuntos ${ }^{1}$, cuya función fue la de recoger el patrimonio dejado por el difunto y hacerlo numerario en pública almoneda, para posteriormente remitirlo a la Casa de la Contratación que por su lado llevaría a cabo todas las diligencias necesarias para localizar a los herederos y hacerles la entrega.

\section{QUIÉNES ERAN ESTOS OFICIALES}

Los expedientes trabajados pertenecen a todos los oficiales de las flotas nacidos en Andalucía o en otras regiones de España, pero que por distintas razones se avecinan en la región, y vienen a fallecer a Indias durante la primera mitad del siglo XVIIL.

Gutierrez Alviz, Faustino: Los Bienex de Difuntos en el derecho indiano. Gavidia Sevilla, 1942. En esta obra se estudia desde el punto de vista legal todo el procedimiento de los Juzgados de Bienes de Difuntos. Ver también Recopilación de las Leves de los Reinos de Indias de 1680. Mandadas a imprimir y a publicar por su Majestad Carólica el Rey Carlos II. Por Solórzano de Pereira. Libro II, Titulo XXXII y Libro IX, Título XIV. 
Los expedientes de Bienes de difuntos localizados son un total de dieciocho. Si bien, este número de oficiales no es elevado respecto a todos los que formaron este colectivo durante dicho periodo, su estudio y conclusiones no deja de ser valioso al construir una variada gama de oficiales, que en distintas flotas Ilegaron a Indias, allí fallecieron solos, lejos de sus seres más queridos, dejando todos sus bienes y posesiones, y que posteriormente tras haberse hecho líquido, serán enviados a la Península para ser entregados a sus herederos.

El mayor número son naturales o vecinos de la provincia de Cádiz, un total de once, le sigue la provincia bética con seis y sólo uno de la de Huelva. Del resto de la región no localizamos a ningún natural o vecino. Sus edades oscilan entre los veintinueve y cuarenta años, un resultado lógico, pues eran las más apropiadas para desarrollar esta actividad, además de que para ocupar alguno de estos cargos se les exigía una edad mínima -por ejemplo mayor de veinticuatro años para desempeñar el de piloto-.

De los dieciocho oficiales analizados, quince son casados, este elevado número obedece claramente a las edades que este grupo tenía, propias de tomar estado, y a los cargos que desempeñaban en los navíos, que les proporcionaba los medios económicos necesarios para poder mantenerla. Asimismo, hallamos un soltero, un viudo, y otro del que desconocemos su situación.

Respecto a su procedencia familiar, todos aparecen como hijos legítimos. Algunos formaron parte de familias numerosas, seis componen la familia a la que pertenece el capitán Joseph Cabrera ${ }^{2}$, otros como el alférez de flota Mathias Gutiérrez ${ }^{3}$ cuenta que tenía un sólo hermano.

Del grupo de los casados y viudos, doce de ellos tienen hijos, el resto o no tienen o lo desconocemos. De manera que de estos oficiales dos tienen un hijo, tres son padre de dos hijos, seis de tres hijos y uno de cinco hijos, aunque hay dos excepciones la de los capitanes Antonio de Ocampo y Diego Ruiz Daza ${ }^{5}$. El primero además de tener dos hijas legitimas, nacidas de su matrimonio legal en Sevilla, tenía otras dos hijas naturales, María y Faustina, fruto de su relación con una dominicana llamada Gregoria López; y el segundo, declara en testamento ser padre de cuatro hijos, tres legítimos, nacidos de su matrimonio y una bastarda, llamada Antonia Flores, nacida de su unión con Francisca Teresa de Flores, vecina de Sevilla con la que no he contraido matrimonio y que vive en la colación Santa Maria Magdalena en la calle de las Virgenes...

Como se observa no es prolija la descendencia de nuestros oficiales. Advertimos que existe una contradicción entre los datos aquí aportados y los estudios hechos sobre la cuantificación de los miembros que componian los núcleos familiares del siglo XVIII, ya que el comportamiento habitual de los matrimonios durante este siglo fue el de tener más de cuatro hijos a lo largo de su vida fértil, aumentando la cifra en

2 Archivo General de Indias (en adelante A.G.1.) Sección de Contratación. Legajo. 983 y 984.

3 A.G.l. Contratación. Leg. 983.

$4 \quad$ A.G.l. Contratación. Leg. $5607 . \mathrm{N}^{\circ} 5$.

5 A.G.I. Eseribania. I.eg. $1060 \mathrm{~A}$. 
etapas de prosperidad económica, como buenas cosechas, comercio, etc., y no en tiempos de decadencia y depresión ${ }^{6}$. La respuesta a esta contradicción, puede ser el tipo de empleo al que estos hombres se dedicaban. La labor que desempeñaban implicaba largas estancias en Indias, que a veces se dilataban durante años en los puertos americanos, lejos de su ciudad y familias, lo que imposibilitaria la concepción de hijos. A esto habría que añadirle los constantes peligros a los que estuvieron expuestos en el mar, como a las innumerables enfermedades que se contagiaban en los puertos indianos, sesgando sus vidas en edades tempranas.

Los cargos más elevados de la tripulación de un barco mercante de la Carrera de Indias, venían representados por los pilotos, maestres y capitanes, cada uno con unas cualidades muy específicas. Sin embargo, a pesar de estas diferencias, a veces, resulta difícil incluir a estos hombres en un grupo u otro, pues en la práctica se observa como en una misma persona recaen varios de estos cargos, el piloto que a la vez es capitán, el capitán que también es maestre y a la vez también es dueño de parte del barco, e incluso para complicar más la estructuración, el maestre que es capitán, dueño de parte del navio donde va ejerciendo su cargo, pero que así mismo es cargador de su embarcación, aclarando en este sentido que no lleva simplemente mercancía para comerciar en Indias -costumbre muy extendida entre los hombres de su condición-, sino que en la documentación aparece como cargador de su navío. Teniendo presente esta cuestión, hemos clasificado profesionalmente a nuestros oficiales según el cargo que van desempeñando en los navíos de las diferentes flotas en las que marchan a Indias, resultando: un ayudante de piloto, dos pilotos, un piloto y capitán, un maestre de permisión, un, maestre, tres maestres que también son también capitanes, siete capitanes, un capitán y cargador de flota y un alférez, todos son oficiales de mar, a excepción de dos que son de mar y guerra.

La mayoría de ellos, un grupo de doce, proceden de un nivel social medio, pues bien es sabido que estos llamados oficiales de mar no eran mas que aquellos que habían alcanzado la cima como trabajadores especializados, ocupando ahora puestos de cierta responsabilidad en los buques mercantes; era el escalafón más alto al que podía llegar un trabajador del mar, por ello, proporcionaba algo más de prestigio social, sin olvidar el origen humilde de estos hombres ${ }^{7}$. Muy distinto era el de los oficiales de mar y guerra, en su mayoría de procedencia noble, de la baja nobleza, y que más que temas náuticos conocían el mundo militar. En un nivel más alto situamos a cuatro de ellos, y en el que destacamos a Cristóbal de Urquijo ${ }^{8}$, pues además de maestre y capitán del navío nombrado San Ignacio, era su dueño en compañía de otro. Dos se adjuntan a un estatus más bajo, como el ayudante de piloto Joseph

6 El profesor Pérez Serrano en su trabajo para el Cádiz del siglo XV1ll, expone que el comportamiento habitual en los matrimonios gaditanos debió de ser de tener una media de seis o siete hijos a lo largo de su vida fértil. En Pére\% Serrano, Julio: Cádiz, la ciudad al desnudo. Universidad de Cádiz. Cádiz, 1992. Familias que estaban lejos de ser macrofamilias de ocho o diez. hijos que se suponia hasta hace unos años como normal en una demografia de Antiguo Régimen. En Garcia-Sanz Marcotegui, Ángel: Demografia y sociedad en la Barranca de Navarra (1760-1860). Gobierno de Navarra. Pamplona, 1985. p. 273.

7 Pèrez-Mallaina, P.E.: Los Hombress del Ucéano. Excelentisima Diputación de Sevilla. Sevilla 1992.. págs. 45 y 48. Gonzále> Rodriguez, Adolfo-Luis: "Armadores y navegantes en la Carrera de Indias en la Scvilla dcl Siglo XVIII". En Actas del 1 Congreso de llistoria de Andalucia. Tomo I. Andalucía Modema. Siglo XVIII. Monte de Piedad y Caja de Ahorros de Córdoba. Córdoba, 1978. pág. 272.

8 A.G.I. Contratación. Leg. 5598. $\mathrm{N}^{\mathrm{a}} 2$. 
Gudiel $^{9}$, claro ejemplo de esta condición social: procede a una familia humilde, los bienes que deja tras su muerte son escasos, e incluso tampoco ocupa el cargo de piloto titular del galeón Nuestra Señora de la Almudena de los Galeones al mando del Conde de Casalegre.

Teniendo en cuenta la estrecha conexión que existe entre la condición social y el nivel cultural, se constata que en la mayoría de los casos viene a coincidir. No obstante el criterio primordial a tener presente será el de si sabían leer y escribir, cuestión que no nos planteamos pues se parte de que a todos los oficiales les era indispensable estos conocimientos para desempeñar su trabajo, además de que para obtener el título de piloto, o de maestre, era necesario pasar una serie de pruebas teóricas y prácticas. Por otro lado, se observa como todo el grupo coincide en realizar en mayor o menor medida prácticas comerciales que implican una serie de conocimientos. De manera, que a un pequeño grupo se le atribuye un nivel cultural medio alto, en el que destaca el capitán Juan del Rio ${ }^{10}$, que junto a su puesto de capitán en uno de los navíos de la flota de Nueva España a cargo del General Manuel de Velasco y Tejada era cargador de dicha flota, además de llevar consigo para su comercio mercaderías de todo tipo e incluso escrituras de riesgo. El resto se integraría en un nivel medio.

Del mismo modo hallamos una gran similitud entre la valoración económica de estos individuos con la condición social, e incluso en mucho de los casos también con la cultural. El principal baremo que vamos a utilizar son los bienes que quedan tras la muerte del oficial, además de aquellos a los que aluden los testigos en sus declaraciones y la contabilización del patrimonio que pudiese tener en su lugar de origen. Se manifiesta la existencia de una relación entre el volumen de bienes con el cargo que ocupan en la flota y sobre todo con el nivel de transacciones comerciales que llevaban a cabo, pues como se dijo todos en mayor o menor medidas realizan estas prácticas que les reportaban unos beneficios extras o complementarios. Uno de los que obtiene un mayor volumen es al capitán Diego Ruiz

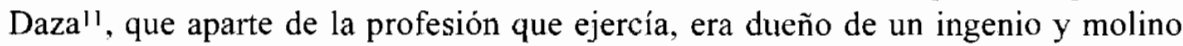
en la Habana, y realizaba todo tipo de actividades mercantiles. Tras su muerte se contabiliza un capital de más de 120.000 pesos escudos; igualmente el capitán y maestre Joseph Cabreras ${ }^{12}$, logra hacerse de un pequeño patrimonio, 10.000 pesos escudos.

Las rutas marítimas que iban haciendo nuestros oficiales coinciden con las más utilizadas a lo largo del siglo XVIII: en primer término la de Nueva España, seguidas de la de Tierra Firme, las del Resto del Continente, y finalmente la de las Islas. Observémoslo en el siguiente cuadro:

\footnotetext{
9 A.G.l. Contratación. Leg. 569. No 9.

10 A.G.I. Contratación. Leg. 568.

11 A.G.1. Escribania. Leg. $1060 \mathrm{~A}$.

12 A.G.I. Contratación. Leg. 983 y $984 . \mathrm{N}^{\circ} 1 \mathrm{R}^{\circ} 1$.
} 
Relación de los mareantes:

$\mathrm{N}^{\circ}$ Nombre

1 Pedro de Jaén

2 Antonio de Ocampo

3 Juan Pérez de Albela

4 Juan del Río

5 Fco. de Paula Domínguez

6 Joseph Gudiel

7 Juan Gutiérrez

8 Gregorio Cerdeño

Monteagudo

9 Joseph Cabreras

10 Felipe de Hoyos Guerrero Capitán

11 Pablo Calvo Pérez Piloto

12 Pedro de Mora y Rendón Capitán

13 Juan de Sangronis

14 Joseph Fdez.

15 Diego Ruiz Daza

16 Cristobal Urquijo

17 Mathías Gutiérrez

18 Nuño de Morla
Capitán

Cargo

Flota

Capitán

Maestre y Capitán

Piloto y Capitán

Capitán

Maestre de Permisión

Ayt. piloto Galeones

Capitán

Piloto

Maestre y Capitán

Maestre

Capitán

Maestre y capitán

Alférez

Capitán
Registro a $\mathrm{St}^{\circ}$. Domingo

Flota. M.Velasco y Tejada

Flota. M. Velasco y Tejada

Azogues. Fdo. Chacón

Conde Casalegre

Flota. .Fdez. Santillán del Castillo

Flota. Andrés de $\mathrm{Pe} z$

Flota. Andrés de Pez

Flota. Andrés de Pez

Flota Juan Esteban de

Ubilla

Flota. Fdo. Chacón

Galeones Baltasar Guevara

Flota Antonio Serrano de Villacañas

Flota. Antonio Serrano

Flota. Rodrigo Torres

Flota Villavicencio

Desde el siglo XVl, los maestres, capitanes y dueños de mercantes tenían un mayor prestigio entre las gentes del mar, que los pilotos. Los primeros, eran considerados como un grupo distinguido, ya que eran los dirigentes del negocio y la navegación de la Carrera de Indias, frente a los pilotos que se les miraba como a simples asalariado.

La legislación mandaba que en cada embarcación deberian de ir dos pilotos ${ }^{13}$, de manera que en la práctica iba el piloto examinado y por otro lado, el maestre que solía ser también piloto. Hay que tener en cuenta que en tan larga y peligrosa trave-

13 La Casa de la Contratación se preocupo desde los inicios de la profesionalidad de los pilolos de la Carrera, por ello, una de sus funciones fue la de preparar y examinar aquellos pilotos que realizarian atguna de las rutas a Indias. 
sía podía ocurrirle algún accidente al piloto, por lo cual debería de sustituirle otro que tuviese parecidos conocimientos, y éste era el maestre.

Entre nuestros hombres de mar, cuatro ocuparon este cargo, entre los que destacan dos: Joseph Gudiel y Juan Pérez de Albela, por ciertas particularidades que pasamos seguidamente a exponer:

Joseph Gudiel14, hacía el viaje como ayudante del piloto principal Felipe del Real, ello quiere decir, que este hombre aún no había conseguido su título de piloto. Este viaje, a semejanza del de nuestros contemporáneos estudiantes de náuticas en sus últimos años, lo realiza en práctica ${ }^{15}$. Nuestro mareante iba embarcado en el galeón Nuestra Señora de la Almudena, de la flota de galeones al mando del Conde de Casa Alegre, que zarpa en 1706, de la bahía gaditana.

Joseph, muere ahogado en Cuba sin redactar ningún tipo de última voluntad, quizás porque la muerte le sorprende, o quizás porque al estar soltero y ser un hombre joven, de poco más de veinte años, preveía el final de sus días aún muy lejos. Como heredera universal de todos sus bienes, cantidad que asciende a más de 800 pesos de permisiones queda su madre Antonia Barba.

Igualmente, Juan Pérez de Albela ${ }^{16}$, marcha ocupando cargo de piloto principal, aunque con la salvedad de que unía también en su persona el de capitán de la almiranta de la Flota del General Manuel de Velasco y Tejada, que leva anclas del puerto gaditano en 1699. La flota permanece varias invernadas en Veracruz, por lo cual, Juan decide residir en una casa sita en la calle Compañia de esta ciudad, lugar donde fallecerá tras padecer una grave enfermedad el 14 de junio de 1701 . Una semana después se procede a redactar el inventario de todos sus bienes. Primeramente se enumeran toda la ropa de su uso, entre ellas destacan las gorgeras con sus balonas de encajes, camisas, calzones, calcetas, escarpines, pues hay que tener en cuenta que el cargo que ostentaba de cierta autoridad en cl barco, marcaría la forma de vestir, muy distinta a la ropas que se pudiera encontrar cuando se tratara de pajes, grumetes o marineros. Se halla también un mosquitero, elemento necesario obviamente por el clima del lugar, y otros objetos comunes localizados en casi todos los inventarios, como eran algunas armas: cuchillos a modo de puñal, una escopeta y pistolas. Pero lo que más nos interesa de este inventario son los elementos propios de piloto que Juan llevaba consigo:

Seis abujas de marear, dos abujas de marcar, dos cartas de marear; un quarteron tres compases, quatro ampolletas, una lanita de laton, un derrotero portugues, un anteojo de larga vista, un martinete pequeño, tres escandalos de plomo y diferentes pedazos de cordel de cañamo para sondaleras, un quadrante...

Posteriormente todo se saca a subasta, obteniéndose como remate final 460 pesos y 3 reales.

14 A.G.l. Contratación. Leg. $569 . \mathrm{N}^{\circ} 9 . \mathrm{R}^{\circ} 5$.

15 Lo cual significa que los seis años de prácticas que se les exigía tener en la ruta para la que queria ser facultado, aún no la habia finalizado

16 A.G.l. Contratación. Leg. $983 . \mathrm{N}^{\mathrm{N}} 3, \mathrm{R}^{\circ} 9$ 
El maestre era la segunda figura en el buque, aunque en la vida real funcionaba como la máxima autoridad. Era usual que el maestre fuese a su vez dueño del barco en el que iba o de parte de él, o socio principal o factor comercial. También tuvieron otras obligaciones, siendo las administrativas las más importantes, como encargarse del abastecimiento y carga del buque. De manera que se convertían en los responsables ante el estado del cumplimiento de las ordenanzas de la Casa de la Contratación, sobre todo en lo referente al pago de impuesto y a evitar el contrabando. El maestre pasaba a ser un intermediario entre los particulares y la administración pública ${ }^{17}$.

Como ya se dijo, en ocasiones los maestres también ocupaban el cargo de capitán. Este es el caso de Antonio de Ocampo ${ }^{18}$, maestre y capitán de una fragata en la que arriba a la isla de Santo Domingo a principios del siglo XVIII. El capitán Ocampo llega a la isla cargado con distintas partidas de mercancía propias y de otros vecinos de Sevilla, con el propósito de negociar. Tras permanecer un tiempo en la isla, decide probar suerte en otro lugar y marcha hacia Cartagena. Años más tarde fallece en Lima.

Antonio estaba casado en Sevilla de donde era vecino con Juana Alfaro, también natural de dicha ciudad, con la que tiene tres hijas: María, Faustina e Isidora. Esta situación no es excusa para que en la isla dominicana se una a otra mujer llamada Gregoria López, se desconoce si fue en este viaje o en otro anterior, lo cierto es que como fruto de esta relación nace una niňa, Juana Antonia, a la que el capitán no sólo no renuncia, sino que atiende y decide cubrirles todas sus necesidades futuras. Con ese fin, adquiere una casa en la isla donde Juana Antonia viviría con su madre, y en la que también residiría una esclava que les serviría. Esta segunda unión hace que Antonio se olvide bastante de su familia peninsular, claro ejemplo de ello son las declaraciones que hace su esposa al dictar testamento, sobre la situación de penurias económicas y calamidades que están pasando, de hecho dice deberle a

Manuel de Rearnos, mercader de Sevilla y dweño de una tienda diferentes cantidades y vales firmados por su hijas procedentes de ropa que habia sacado de su tienda para vestir a sus hijas, para sustento y cosas necesarias para el mantenimiento de su familia con la condicion de que le serían pagada de su monto luego que viniese a España su marido.

A pesar de todo Antonio dice que no olvidó a su descendencia legítima, pues cuando llega el momento de que sus hijas tomen estado les envía cierta cantidad para socorrerlas.

Por sus bienes queda la cantidad de 1.065 pesos y la casa que el difunto compró en Santo Domingo. El dinero será cobrado por los nietos legítimos -hijos de sus hijas sevillanas-; y el inmueble quedará para sus nietos naturales tras demostrar los derechos que tenían sobre ella.

Los capitanes cerraban el grupo de poder que iban al frente de un barco. Su misión consistía en la defensa del buque. En caso de ataque, el maestre y el piloto

17 Pérez-Mallaina, P.E.: Pothica naval española el Atlantico 1700-17/5. Escuela de Estudios Hispanoamericanos. Sevilla, 1982. pág. 287.

18 A.G.L. Contratación. Leg. $5607 . N^{\circ} 5$. 
quedaban sometidos a la autoridad del capitán, pero si no era por esta causa, éste no podía inmiscuirse en los asuntos náuticos ni comerciales de la embarcación.

Uno de estos capitanes es Juan Gutiérrez del Castillo ${ }^{19}$. Juan fallece en el viaje de regreso, camino a la Habana, iba ocupando este puesto en un bergantín de la Flota del General Diego Fernández de Santillán,. Coincidiendo con la mayoría de los hombres de similar cargo, también llevaba artículos para vender en Indias. En este caso la mercadería -aguardiente, ropa, etc.- la llevaba a medias con un piloto de otro de los navíos de la misma Flota, que además era paisano - pues ambos eran naturales de Sanlúcar de Barrameda- un tal Matheo Cales. Cuando Juan comienza el tornaviaje y conociendo que el barco donde iba Matheos alcanzaría antes las costas cubanas que el suyo, decide encargarle a éste toda la mercadería con el objeto de ir adelantando las ventas en la isla, sacando así los mayores beneficios posibles. El problema surge cuando Juan encontrándose muy enfermo, fallece antes de recalar en el puerto habanero, de manera que su compañero se queda con todas las ganancias de las ventas, más de 2.000 pesos, además de otras mercaderías cuyo valor podría ascender aproximadamente a los 5.00006 .000 pesos escudos, según declaraciones de sus herederas. Tras conocerse la noticia, en la localidad de Sanlúcar se inicia un pleito entre los apoderados de los herederos y el socio del difunto. La primera parte reclama insistentemente que Matheo entregue las cuentas de las ventas. El piloto hace caso omiso a tal demanda y presenta un certificado de enfermedad, donde asegura padecer una dolencia que le impide realizar las gestiones que se le solicitan. Pero ante la reiterada petición de los herederos, junto a las muchas presiones y plazos dados por las autoridades bajo amenaza de cárcel, Matheo responde presentado una declaración jurada de los bienes que llevó, eso sí, sujeta a su memoria, pues declara que extravió las cuentas que le entregaron las autoridades cubanas sobre el inventario del difunto capitán.

Por otro lado, localizamos a oficiales que podríamos incluir en otro género, puesto que además de ser maestres y capitanes formaban parte de un grupo aún con mayor fuerza, pues eran propietarios de parte de los barcos donde iban, y esto les hacía tomar las decisiones más importante. Estos capitanes podían ser considerados según la terminología del Siglo XVI como señores de nao, término muy usada por el profesor Pablo Emilio Pérez-Mallaína ${ }^{20}$, pues estos capitanes, navegaban en los barcos de los que eran propietarios y a los que dirigían.

Uno de estos señores de nao era Josep Cabrera ${ }^{21}$. Joseph era dueño de la mitad del navío donde va ejerciendo los puestos de maestre y capitán, el Nuestra Señora del Rosario y San Joseph. En esta ocasión, nuestro hombre va en la Flota que se hace a la mar en 1708 al mando del General Andrés de Pez.

Para este viaje llevaba consignado distintos tipos de mercaderías, y de escrituras de obligación firmadas por vecinos de Sevilla con el propósito de hacer el viaje más productivo. Además de otros negocios nuestro capitán obtenía ingresos procedentes del pasaje que cobraba a los particulares que hacían el viaje en su barco, al ser dueño,

19 A.G.1. Contratación. Leg. 983.

20 Pérez-Mallaina, P.E.: Los hombres del max... pág.97.

21 A.G.1. Contratación. Leg. 983 y $984 . N^{\circ} 1 . R^{\circ} 1$. 
capitán y maestre del navio ostentaría este derecho, aunque también la obligación de pagarle la soldada a toda su tripulación. Joseph fallece el 28 de septiembre no sin antes dictar un poder testamentario.

Como hemos podido comprobar, prácticamente todos los oficiales llevaban a cabo transacciones comerciales en mayor o menos medida que les reportaban unos beneficios extras. Sin embargo, localizamos un pequeño grupo que se distinguen del resto puesto que son claramente comerciantes o cargadores. El ejemplo más ilustrativo es un coruñés avecindado en Sanlúcar llamado Juan del Rio ${ }^{22}$. Juan era capitán del Santo Cristo del Buen Viaje, barco que pertenecía a la Flota de Nueva España de 1699 a cargo de Manuel de Velasco y Tejada. Al parecer, su profesión le venía de familia, pues era hijo de otro capitán de la flota, Vicente del Rio. En el último viaje que realiza, nuestro capitán va también como cargador de la Flota, llevaba numerosas mercancías consignadas, escrituras de riesgos, etc. Durante su estancia en Indias reside en la calle Vicaria de la ciudad de Veracruz, en una casa particular, lugar en donde es atendido en su grave enfermedad y donde más tarde fallece el 7 de junio de 1701 .

Si hasta aquí se han analizado los cargos vinculados a los navíos mercantes, también se localizan individuos, que fueron ejerciendo sus funciones en los barcos de la Armada que iban protegiendo a los mercantes de la Carrera. Muestra de ello es el capitán de mar y guerra Nuño Morla de Villavicencio ${ }^{23}$. Los capitanes de mar y guerra detentaban sin limitación la autoridad de sus embarcaciones, eran militares profesionales, aunque ya para 1717 con la creación de la Escuela de Guardiamarina de Cádiz estos cargos cada vez se van profesionalizando más.

El cumplimiento de todos estos cargos, era recompensados económicamente por un salario, o soldada. El capitán y maestre, Joseph Cabreras ${ }^{24}$, nos da una relación de los salarios que cobra su tripulación, con ruta a Nueva España, de la que entresacamos los 900 pesos que ganaba el piloto; o los 113 pesos y medio real del ayudante de piloto.

El salario de las tripulaciones de los buques mercantes se cobraba en dos pagos. El primero se realizaba antes de zarpar el navio del puerto peninsular, se le llamaba socorro o préstamo y consistía casi siempre en el adelanto de parte del salario. Un segundo pago se percibiría una vez se llegaba y la embarcación este amarrada en el puerto, esta segunda entrega equivaldría a lo restante de la soldada.

Por el contrario los salarios de las tripulaciones de los navíos de escolta se pagaban mensualmente, cobrándose de dos a cuatro pagas por adelantado antes de zarpar hacia Indias. Para el siglo XVIII, un capitán de infantería solía cobrar al mes 40 escudos, teniendo los mayores salarios los almirantes y generales, que cobraban entre 100 y 200 ducados respectivamente cuando el viaje era a Nueva España25.

22 A.G.l. Contratación. Leg. $568 \cdot \mathrm{N}^{\mathrm{D}} 6 \cdot \mathrm{R}^{\circ} 4$.

23 A.G.1. Contratación. Leg. $466 . \mathrm{N}^{\circ} 4 \mathrm{R}^{\circ} 4$.

24 A.G.I. Contratación. Leg. 983 y $984 . \mathrm{N}^{\circ} 1 \mathrm{R}^{\circ} \mathrm{L}$.

25 Gil-Bemejo, Juana y Pérez-Mallaina, Pabio Emilio: "Andaluces en la navegación trasatlántica: vida y muerte èn la Carrera de Indias en el siglo XVIIl". En IV Jornadas de Andaltucia y America en el siglo XVIII. Universidad Santa María La Rábida. Sevilla, 1985. pág. 278. 
Lo acostumbrado y establecido por la ley era que cuando el marino fallecía durante el viaje o en algún puerto americano, la soldada se ajustaba según la parte del viaje que había sido realizado. Sin embargo, en ocasiones no se cumplió. Hubo excepciones por distintos motivos, como podía ser la amistad, o cualquier otra causa, entregándose mayor cantidad de lo que le correspondía. Para comprenderlo, veamos el caso del maestre Joseph Fernández de Villacañas ${ }^{26}$. Joseph va ocupando dicho mando en el navio Nuestra Señora del Rosario, San Cristobal y San Antonio, uno de los de conserva del General Antonio Serrano, con el que había firmado un contrato por un viaje redondo concertando su salario en 1000 pesos. Joseph al llegar a Veracruz enferma y fallece, solo realiza la mitad del viaje, sin embargo, el capitán del navío Don Gregorio de Requena y el dueño de dicho navío Don Bernardo de Peralta y Córdoba, por la gran amistad y aprecio que les unia y según dice teniendo en cuenta el trabajo de fletar y firmar conocimientos, se le ajusta como soldada devengada para que cobren sus herederos, dos terceras partes del viaje, un total de 666 pesos y 5.5 reales.

Además de los salarios, a las tripulaciones tanto de los navíos mercantes como a las de guerra se les entregaba una ración de comida y vino diarias ${ }^{27}$. Esta última y siguiendo la costumbre de la época no era consumida, sino que se conservaba para ser vendida al llegar a los puertos americanos, por el alto precio que estos caldos alcanzaban en América.

A todas estas compensaciones habría que añadir otra fundamental, y es que América siempre brindó la posibilidad de conseguir una cantidad extraordinaria que iba relacionada con la práctica de alguna actividad mercantil en mayor o menor medida.

Todos estos ingresos serían los que sustentarían a las familias que quedaban en la Península, el medio de subsistencia. Ahora bien, en más de una ocasión las localizamos viviendo en una situación de penurias y calamidades, la razón deriva de la intención que ponen algunos de los mareantes en reunir el mayor caudal posible a la hora de zarpar, para asi realizar el mayor número de transacciones comerciales posibles. Pues en el fondo de los corazones de estos hombres siempre existió la idea de lograr ese golpe de suerte que les confiriese un cambio de su destino.

\section{MUERTE Y HONRAS FÚNEBRES}

A excepción de cuatro de estos andaluces que mueren ahogados o desconocemos las causas de sus muertes, el resto fallece tras padecer una grave enfermedad. Hay

26. A.G.I. Contratación. Leg. 5587. No $3 . \mathrm{R}^{\circ} 3$.

27 Conocemos que para 1702, una botija de vino cubierlo en Veracruz valia 9 pesos y de vino blanco 11 pesos. En 1709 un barril de vino tinto en Veracruz salia por 44 pesos y una botija de vino tinto 13 pesos 4 reales. Mientras que en la peninsula para $17 / 2$ un barril de aguardiente costaba 16 pesos. A.G.I. Contratación. Leg. 569. N'4. $\mathrm{R}^{\circ} 4$ : Leg. 983 y $984 \mathrm{~N}^{\circ} 1 . \mathrm{R}^{\circ} \mathrm{I} ; \mathrm{Lcg} .984 . \mathrm{N}^{\circ} 3 . \mathrm{R}^{\circ} 2$.

Para el período de 1719-1735, se produce en toda la peninsula un aumento de la produceion agricola, pues se aumentan los cultivos. Para estos años los precios dei vino suben en contraste con los del trigo, originando un ineremento de la extensión dedicada al viñedo. En Plaza Prieto, Juan: Estructura económica de España en el siglo XVHI. Confederación Española de Cajas de Ahorros. Madrid. 1976. pág. 938. 
que tener en cuenta que a la peligrosa travesía a Indias se le unía el arribo a los puertos americanos, lugar de llegada no sólo de gentes, sino también de enfermedades. Señalamos el insalubre puerto de Veracruz como centro de propagación de epidemias.

Cuando enfermaban y las posibilidades económicas lo permitian, nuestros oficiales en vez de ser ingresados en hospitales -era lo más habitual entre los hombres del mar- eran atendidos de sus afecciones en casas particulares, en las que reciben los cuidados y atenciones de médicos o mujeres, como le ocurrió al capitán y maestre Joseph Cabrera ${ }^{28}$, quien durante los veintiún días que dura su mortal enfermedad recibe las atenciones de una mujer a la que se le paga un peso por día. Podía darse el caso que fuesen los propios compañeros o paisanos los que se encargasen de los cuidados, así se observa como el maestre Joseph Fernández de Villacañas ${ }^{29}$ es asistido en su dolencia por el capitán y dueño del navío en el que iba, Don Pedro de Bernardo y Peralta de Córdoba.

La legislación aconsejaba a los hombres de mar a dejar constancia por escrito de sus últimas voluntades antes de iniciar un largo viaje, por los múltiples peligros que la travesía conllevaba. Sin embargo, son sólo tres los que lo hacen Juan del Rio, Pedro de Mora y Rendon ${ }^{30}$, y Diego Ruiz Daza ${ }^{31}$. En el caso del primero Juan del Rio, tras su óbito se tiene noticia de que había dictado en Veracruz un testamento cerrado, pero ante la necesidad de conocer el nombre del albacea, para proceder a llevar a cabo el entierro y demás honras, se ordena por el General de la Flota abrirlo ante testigos. Como albacea, el capitán había designado a su esposa Josepha Ramos Cavello, a un vecino de Sanlúcar y a un paisano y residente en Veracruz, además de ser también cargador de dicha flota, Tomas Cloque. Pero por otro lado, también se conoce que Juan anteriormente había redactado otra disposición testamentaria en Sanlúcar, su ciudad natal. Pues bien, aquí hay un hecho a destacar y es que a su viuda Josepha Ramos Cavello, y a sus dos hijas menores Isabel y Catalina, le llega la noticia de la muerte de su marido y padre muy tempranamente, de boca de otro capitán y amigo de un navío de aviso, por lo que ya en Sanlúcar, por orden del gobernador de dicha ciudad se ordena comience todo el procedimiento. Suponemos que la familia no tenía conocimiento de que Juan había dispuesto otro testamento en México antes de fallecer, y en donde revocaba el primero hecho en Sanlúcar, excepto cn lo referente a las mandas religiosas.

El resto de nuestros protagonistas al percibir que se acercaba el final de sus días deciden redactar testamentos, algunos incluso por la falta de tiempo entregan poderes o incluso ordenan memorias testamentarias. Esto es lo que le ocurre al piloto Juan Perez de Albela tras enfermar de gravedad en la ciudad de Veracruz debido a la gravedad de mi enfermedad no me da lugar a testar en la forma y con el espacio que se requiere las cosas del descargo de mi conciencia, y por ello, un día antes de fallecer -el 14 de junio de 1701- otorga un poder para testar, nombrando como única y uni-

\footnotetext{
28 A.G.I. Contratación. Leg. 983 y $984 . \mathrm{N}^{\circ} 1 . \mathrm{R}^{\circ} 1$.

29 A.G.1. Contratación. Leg. 5587. N ${ }^{\circ} 3 . \mathrm{R}^{\circ} 3$.

30 A.G.I. Contratación. Leg. 5587.

31 A.G.I. Escribania. Leg. 1060 A.
} 
versal heredera a su hija, y como tutora y curadora de ella a su esposa, a la cual releva de fianza porque sabe de su buen obrar. De igual manera en este poder nombra como albacea a un vecino de Veracruz Luis de Montes y a dos capitanes de la Flota: Juan Berroa y Miguel Castellano, suponemos que al ser hombres de su entorno y de su misma condición social les inspiraría mayor confianza para dejarles encargadas sus últimas voluntades.

A partir del estudio de las cláusulas espirituales de los que hicieron testamentos u otras disposiciones, se ha podido analizar todo lo relacionado con la religiosidad de estos individuos, de manera que señalamos que: son pocos los que disponen el lugar donde quieren recibir sepultura, así como el tipo de hábito con el que quieren ser enterrados, siendo el más solicitado el del Seráfico Padre San Francisco ${ }^{32}$; casi todos coinciden en demandar una misa de réquiem el día del entierro; algunos disponen misas por su alma, señalamos desde las 12 misas que ordena el piloto Pablo Calvo Perez $^{33}$ se digan en la iglesia parroquial de Veracruz, hasta las 4.000 que solicita el capitán Diego Ruiz Daza ${ }^{34}$ repartidas entre iglesias de Veracruz y de Sevilla; son escasas las mandas pías, quizás por los cortos patrimonios de los que estos hombres eran titulares. De entre ellas señalamos las del capitán Joseph Cabreras ${ }^{35}$ que deja 1.500 ducados para dotar a doncellas pobres de Castilleja -Sevilla- de donde él era natural.

\section{LAS RELACIONES PERSONALES Y LOS SENTIMIENTOS EN LA CARRERA DE INDIAS}

Casi todos los oficiales andaluces estudiados, debido a las condiciones que su profesión les exigía, embarcaban solos, de ahí que en la mayoría de los expedientes se denotan fuertes lazos de paisanaje entre los que iban en el mismo convoy, al encontrarse fuera de sus hogares y solos, se producia un fortalecimiento de este vínculo. Esta era la razón de que entre ellos se ayudarán en todo momento, sobre todo en los mas difíciles, cuando enfermaban y sentían que la vida se les escapaba. En ellos buscaban no sólo sus cuidados, sino el amparo de unas personas que de una forma u otra les hacían sentirse más cercanos a sus seres queridos, o al lugar de origen, les reconfortasen en esos difíciles momentos y les den la mano para dar el paso al más allá; y son a esos compañeros-paisanos los que los moribundos en muchas ocasiones elegían como albaceas, rogándoles que dispusieran sus honras fúnebres, que le hiciera llegar sus bienes a los seres queridos, que cuidasen de ellos, etc. Esto se pone de manifiesto en el caso del piloto Gregorio Cerdeño Monteagudo ${ }^{36}$ que

31 A.G.I. Contratación. Lcg. 983 y 984.

32 Esta elección se debia a varias racones como eran las indulgencias concedidas por diferentes Papas a los que se enterraban con dicho hábito, al carácter interecsor que tenia San Francisco para las almas del Purgatorio, o a la popularidad que este Santo tenía, pues se le consideraba como a un segundo Cristo encarnado.

A.G.l. Contratación. Leg. 984

34 A.G.I. Escribania. Leg. 1060 A.

35 A.G.I. Contratación. Leg. 983 y 984.

36 A.G.I. Contratación. Leg. 983. 
nombra albacea a dos amigos, compañeros y paisanos -Gerónimo Domínguez Gallego y Francisco Sánchez-, para que ambos ordenaran su testamento, encargándoles a ellos que dispusiesen sus honras fúnebres. También podía darse el caso de que se ayudasen económicamente prestándose dinero, hechos que observamos en los testamentos cuando declaran sus deudas o débitos.

El fortalecimiento de las relaciones de paisanaje y compañerismo tuvo su lado negativo, y es que en ocasiones provocó una relajación de los lazos con la familia peninsular, aunque también es cierto que en contados casos se desligaron totalmente de ésta. Muestra de ello son los testamentos, poderes testamentarios o cualquier tipo de disposición que aparecen en los expedientes en los que cuando se designa a los herederos, siempre recuerdan a los hijos, esposas, padres, sobrinos, o a cualquier otro familiar que quedó en la Península. La correspondencia que aparece en algunos de los autos entre el difunto y sus familiares es otro ejemplo que prueba como casi nunca se llegó a romper totalmente con los que quedaron en la tierra natal. El piloto Pablo Calvo Pére $z^{37}$, al encontrarse muy enfermo y lejos de su casa -en Veracruz- dicta testamento, al no tener hijos, nombra por su heredera legitima a su madre Maria Bermejo, y si esta hubiera fallecido a sus dos hermanos, pero además a su esposa Juana Pérez por lo que la estima y para alivio de su viudes le lega el quinto de sus bienes. Tras llegar la herencia a Cádiz, y llevarse a cabo todo el procedimiento para la entrega, el apoderado de la viuda hace alusión a varias cartas que aparecen en el inventario de los bienes del difunto, en las cuales se dice que el piloto envió desde México a su esposa distintas cantidades de dinero, de manos de un amigo y vecino de Cádiz. Con ellas se demuestra la estima y preocupación del piloto para que su mujer no pasase ningún tipo de penuria. Estas misivas revelan que a pesar de la distancia y las dificultades para comunicarse, se sigue lo mas cerca posible la vida de los seres más queridos, así tenemos constancias de que el capitán Felipe de Hoyos Guertero ${ }^{38}$ en su última disposición declara tener dos hijos, y que la menor se llama María y que tiene menos de un año, ya que nació cuando el ya había partido. Este hecho revela que Felipe tuvo comunicación o noticias con su familia después de zarpar.

A modo de conclusión, creemos haber mostrado, por supuesto, a partir de las pinceladas dadas a la historia de las vidas de estos hombres, lo que pudo ser su existencia, cómo vivian y sentían, cómo hacían para sacar los mayores beneficios a su trabajo y cómo morian. Se trata de un tipo determinado de hombres, los oficiales, cuyo medio de vida fue la Carrera de lndias, lo cual implicaba un modo de vida especifico y que evidentemente repercutía en la estructura familiar peninsular, e incluso a veces también en la indiana cuando existían lazos de consanguinidad.

37 A.G.I. Contratación. Leg. 984. No $3 \mathrm{R}^{\circ} 2$.

38 A.G.L. Contratación. Leg. 673. 